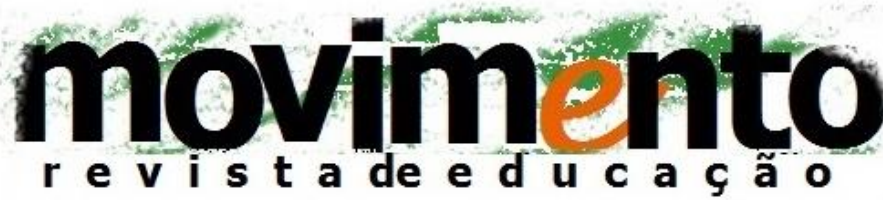

faculdade de educação - programa de pós-graduação em educação

universidade federal fluminense

issn 2359-3296

ano 3 número 5 - 2016

\section{POLÍTICAS PÚBLICAS, ESTADO E EDUCAÇÃO: notas a partir dos escritos de Gramsci}

\author{
Anita Helena Schlesener ${ }^{1}$
}

\section{RESUMO}

Tomando como referência os escritos de Antonio Gramsci o objetivo desse artigo é tecer algumas considerações sobre os limites e possibilidades das políticas públicas no contexto das democracias modernas, articulando com os conceitos de Estado e educação. A estrutura da democracia moderna permite gerar a ilusão de participação efetiva dos subalternos. A dimensão ideológica da hegemonia consolida as relações de dependência. O objetivo de Gramsci é esclarecer a noção de hegemonia para criar novas condições de confronto político para as classes dominadas.

Palavras-chave: políticas públicas, Estado, educação, Gramsci.

\section{ABSTRACT}

Taking es reference Antonio Gramscis's Writings, the objective of this article is to weave some considerations about limits and possibilities of public policies of the modern democracies coordinating with state and educational concepts. The structure of moderns democracy allows to generate the illusion of effective participation of subaltern. The ideological dimension of hegemony reinforce dependency relationships. Gramsci's intention is to clarify the hegemony notion to create news conditions of confrontation politician for the dominate class.

Keywords: public politics, State, education, Gramsci.

\footnotetext{
1 Professora de filosofia política e de estética da UFPR; atualmente docente do Programa de Mestrado e Doutorado em Educação da UTP de Curitiba; cursando Pós-doutorado em Educação na UNICAMP.
} 


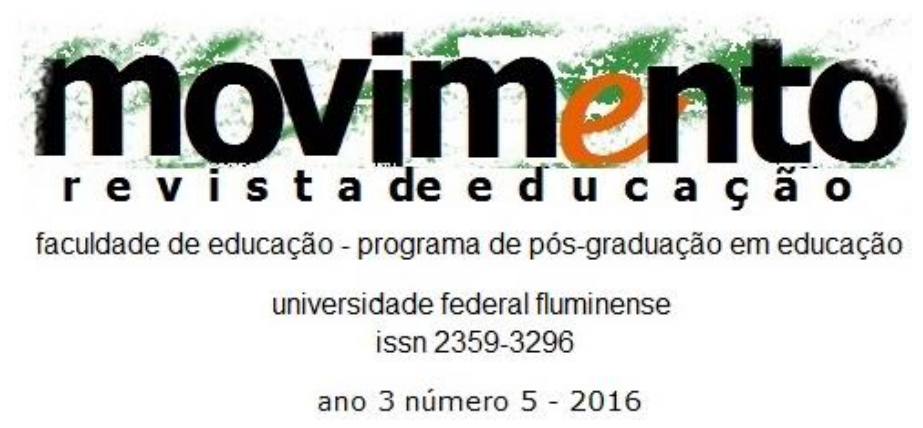

\section{Introdução}

O presente artigo pretende desenvolver algumas reflexões sobre políticas públicas e Estado, com desdobramentos nos projetos educacionais voltados à formação política dos trabalhadores, tendo como referencial principal os escritos de Gramsci. As questões principais que se apresentam são: existem possibilidades de responder aos interesses das classes subalternas no contexto estrutural da democracia burguesa? Como Gramsci explicita a força e a fragilidade do Estado liberal e como entender a efetivação das políticas públicas neste contexto? Como se instauram as relações de força que possibilitam às classes subalternas avançar na sua luta por novas relações de hegemonia?

Embora os escritos de Gramsci sejam contextualizados e resultantes de polêmicas inseridas na realidade italiana do início do século $X X$, o cenário político por ele analisado não se distancia da realidade presente, salvo as novas características da crise econômica, que são geradas basicamente por um sistema de financeirização da economia.

Muito já se escreveu sobre este assunto e não pretendemos apresentar aqui uma formulação original sobre o tema. Apenas para contextualizar a questão dos limites e possibilidades das políticas públicas, retomamos alguns pontos fundamentais da política neoliberal implementada a partir da década de 70 e que teve como uma de suas metas renovar a correlação de forças econômicas mundiais redefinindo a posição dos Estados nacionais em relação ao processo de internacionalização da economia. 


\section{movimento \\ faculdade de educação - programa de pós-graduação em educação \\ universidade federal fluminense issn 2359-3296 \\ ano 3 número 5 - 2016}

A crise do capitalismo foi apresentada à sociedade em geral como crise do Estado que, conforme os defensores dessa política, deveria ter suas funções diminuídas a fim de resolver a crise. A pretexto de controlar a inflação e redimensionar a aplicação dos recursos públicos, instaurou-se uma política de contenção dos investimentos voltados à regulamentação dos direitos sociais que, ao lado do nível crescente de desemprego e aumento da especulação financeira, gerou um aprofundamento das desigualdades sociais e um aumento exacerbado da exclusão social. A longo prazo, estas medidas mostraram o verdadeiro caráter da nova fase do capitalismo que se implementava, com privatizações, ajustes fiscais acompanhados da dependência dos fundos (FMI, BM), desregulamentação dos fluxos financeiros (um capital que gira sem controle do Estado e que, desta forma, também pode fugir do fisco), com danos graves ao processo produtivo.

Este discurso foi ainda acompanhado pelas ideias de "globalização" e de "mundialização da economia", ideias que auxiliaram a mistificação inicial deste processo de reformas. Lea Durante (2000/2001, p. 86), estudiosa da questão internacional em Gramsci, acentua que mundialização precisa ser entendida como a "atual fase de expansão transnacional da economia", com uma clara "dimensão ideológica", que se apresenta na "transferência dos poderes reais e da hegemonia dos Estados para as empresas". Ou seja, o capitalismo toma uma nova dimensão transnacional que exige uma redefiniçao da função dos Estados nacionais na sua gestão da economia. A dimensão ideológica se apresenta na "positividade da divisão internacional do trabalho como fator de progresso para as áreas menos desenvolvidas" e na "esperança de um reconhecimento cada vez mais amplo dos direitos civis e assim por diante".

Esta realidade atingiu o Brasil a partir da década de 90 e do Plano real e, apesar 


\section{movimento \\ faculdade de educação - programa de pós-graduação em educação \\ universidade federal fluminense issn 2359-3296 \\ ano 3 número 5 - 2016}

do "interregno" da política do Partido dos Trabalhadores, as alianças feitas pelo partido, mais conservadoras a cada nova eleição, ligadas à crise do capitalismo internacional que chegou ao país nos últimos anos, nos mostram hoje a função devastadora das políticas neoliberais. As novas políticas recessivas visam a restringir ainda mais os compromissos sociais do Estado para restaurar, "por intermédio do resgate do programa neoliberal ortodoxo do século passado restaurar a hegemonia no bloco no poder do grande capital internacional e da fração da burguesia brasileira a ele integrada" (BOITO, 2016).

A partir deste contexto, apresentamos algumas notas sobre o Estado e sua função a partir dos escritos de Gramsci, a fim de mostrar os limites de participação das classes subalternas no sistema democrático burguês, bem como as ilusões geradas pela ideia de que as políticas públicas podem trazer mudanças fundamentais. A abordagem gramsciana a partir das relações de força permitem explicitar as condições de luta pela hegemonia.

Em seguida, abordamos os limites e possibilidades de mudança a partir das políticas públicas no contexto da democracia burguesa. Os limites se apresentam tanto na forma de gestão pública a partir da estrutura parlamentar, quanto pelos mecanismos de influência que possui a classe dominante a partir da estrutura econômica e das desigualdades sociais.

Finalmente concluímos com algumas observações a propósito da importância da educação das classes subalternas e de sua organização política para um equilíbrio nas relações de força que é preciso enfrentar para alguma possível conquista, acentuando que este processo educativo implica entender 0 movimento estrutural e conjuntural da realidade na qual vivemos. 


\section{movimento \\ faculdade de educação - programa de pós-graduação em educação \\ universidade federal fluminense issn 2359-3296 \\ ano 3 número 5 - 2016}

Notas sobre o Estado a partir de Gramsci:

Como ideia-limite o programa liberal cria o Estado ético, isto é, um Estado que idealmente está acima das competições de classe, da interrelação e embate de agrupamentos que compõe a realidade econômica e tradicional (GRAMSCI, 1975, p. 75).

Uma das forças do pensamento liberal na sua assimilação pelo senso comum está na abordagem abstrata dos conceitos, ou seja, na sua significação parcial na medida em que se ocultam os conflitos e a desigualdade social gerada pela divisão social do trabalho. O ideário liberal sedimenta-se na forma sem conteúdo ou no discurso sem base na realidade e, desse modo, elabora o imaginário social a fim de consolidar um modo de pensar homogêneo. A noção de direito na sociedade capitalista, por exemplo, tem como pressuposto uma igualdade irreal a partir da premissa de que "todos os cidadãos devam aceitar livremente o conformismo apontado pelo direito, enquanto todos possam tornar-se elementos da classe dirigente" (GRAMSCI, Q. 6, p. 773), o que é dificílimo de ocorrer em função dos pressupostos ocultos.

Desta forma, na sociedade de classes, o direito não exprime toda a sociedade, mas "a classe dirigente, que 'impõe' a toda a sociedade aquelas normas de conduta que são mais ligadas à sua razão de ser e ao seu desenvolvimento" (GRAMSCI, 1978, p. 73). Tal se concretiza na medida em que a ideia de igualdade se firma no imaginário social a partir da imagem de um sujeito individual cujos interesses privados nada tem em relação com o social. Assim, o direito tem uma função importante de educação das massas, de "conformação" às exigências colocadas pelo modo de produção capitalista: "por meio do 


\section{movimento \\ faculdade de educação - programa de pós-graduação em educação \\ universidade federal fluminense issn 2359-3296 \\ ano 3 número 5 - 2016}

'direito', o Estado torna 'homogêneo' o grupo dominante e tende a criar um conformismo social útil ao desenvolvimento do grupo dirigente" (Q. 6, p. 757).

O mesmo acontece com o conceito de liberdade: na modernidade a organização de base jurídica tem como objetivo garantir direitos subjetivos cuja expressão se encontra no exercício da liberdade. Já Benjamin Constant, em 1819, fazia a comparação entre a liberdade dos antigos e a dos modernos, mostrando que a liberdade dos antigos se consolidava nas relações políticas e na participação nas decisões de Governo; a modernidade inverteu essa situação e consolidou a liberdade enquanto direito individual de cuidar e defender os interesses privados e tornou as instâncias política e jurídica como garantidoras desses direitos. Marx esclarece na Questão Judaica que esta garantia de independência individual e privada consolidada na sociedade capitalista se traduz basicamente em garantia e segurança da propriedade privada.

Gramsci, apoiado em Marx, acentua a função específica do direito de garantir a liberdade individual restrita ao agir autônomo na esfera privada e, a partir do ocultamento das desigualdades sociais, que tem sua base no modo de produção e na exploração da força de trabalho, gerar a ilusão de igualdade e de participação equitativa na estrutura da sociedade, criando expectativas sociais que nunca se concretizarão. Primeiro, não existe uma natureza humana constitutiva da liberdade, visto que somos historicamente condicionados e nos fazemos no processo de socialização no qual conquistamos a liberdade (GRAMSCI, 1978), (o que põe em cheque a ideia de meritocracia). Segundo, existe um ardil na própria proposição da ideia de liberdade: para ser livre, na sociedade capitalista, é preciso ser proprietário, mas a riqueza não pode aparecer como o objetivo principal; "a riqueza não é um fim; se se torna um fim, 


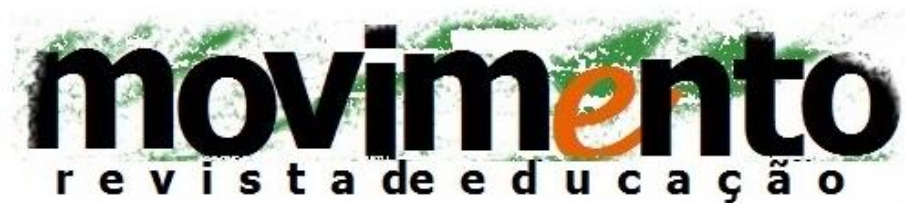 \\ faculdade de educação - programa de pós-graduação em educação \\ universidade federal fluminense issn 2359-3296 \\ ano 3 número 5 - 2016}

chama-se avidez (avareza)", ou seja, moralmente condenável. A riqueza precisa apresentar-se como "meio para um fim: a liberdade" (GRAMSCI, 1975, p. 215).

Este conjunto de premissas leva os homens comuns a acreditarem que, por suas qualidades individuais, podem ter acesso à riqueza pelo trabalho, ou seja, sonham em ascender socialmente acumulando riqueza, sem saber que, para enriquecer nesta sociedade se faz necessário possuir a propriedade dos meios de produção. A liberdade, na sociedade capitalista, é um privilegio (GRAMSCI, 1975).

Outro efeito mistificador que sofrem os conceitos se encontra no processo de mutação dos seus significados a partir do momento em que são naturalizados e submetidos às ideias cristalizadas de "bem em si" e de "mal em si". Neste caso, o ideário liberal se mistura com tradições arcaicas transmitidas de geração em geração e que formam o cotidiano familiar e religioso. Perde-se a dimensão histórica da vida e das relações em geral, reduzindo ao individual subjetivo "natural" questões sociais como, por exemplo, a violência, a exclusão e todos os reveses que possam acontecer. $O$ senso comum entende a realidade a partir de oposições dualistas estáticas, apega-se ao instituído e às garantias mínimas que este oferece, atribuindo as contradições, que são sociais, a um "mal" abstrato e não identificável materialmente.

O pensamento liberal se beneficia desta situação na sua argumentação geral em defesa da liberdade individual, colocada a partir de características naturais e subjetivas, centradas no individualismo meritocrático. Este ideário liberal que forma o senso comum garante a passividade política e a aceitação da ordem social vigente. A ele se alia a separação entre economia e política, fundada na abstração da própria ideia de Estado como uma instância acima da sociedade 


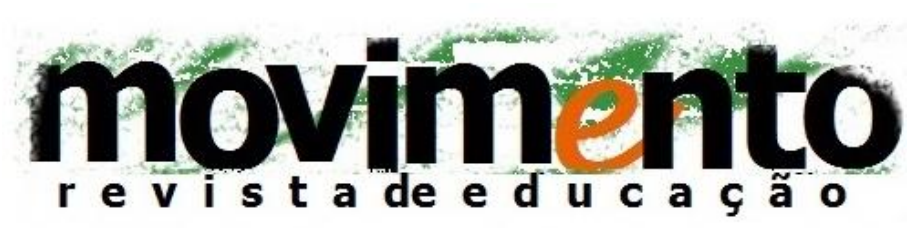

faculdade de educação - programa de pós-graduação em educação

universidade federal fluminense issn 2359-3296

ano 3 número 5 - 2016

que tudo controla e garante. Com esta abstração o Estado liberal garante a livre iniciativa da economia na esfera privada e no mercado, fatores necessários para a acumulação do capital.

A crítica gramsciana a esta estrutura econômica, social e política permeia todos os escritos desde 1916 até os Cadernos do Cárcere, mostrando como o ideário liberal oculta e mistifica a função do Estado enquanto poder de classe, exercendo enorme influência na formação do senso comum. Na sociedade capitalista, o exercício do poder se enraíza na divisão da sociedade em classes sociais antagônicas e o Estado defende interesses da classe dominante e, ao mistificar e dissimular a sua verdadeira função, contribui para garantir e ampliar as formas de dominação.

Abordamos a seguir alguns momentos em que esta crítica se efetua: poderíamos aqui iniciar pelo conceito de hegemonia, mas entendemos que um dos momentos mais importantes para esclarecer esta questão se encontra na definição gramsciana de Estado. Se o pensamento liberal entende o Estado como o mero aparato administrativo e burocrático que constitui a esfera do poder governamental, Gramsci entende o Estado como articulação entre sociedade política e sociedade civil, ou seja, o Estado se caracteriza pelo conjunto da sociedade, em suas relações econômicas, sociais, políticas e ideológicas.

A noção gramsciana de Estado se explicita ao longo dos Cadernos, dos quais selecionamos alguns fragmentos para identificar a estrutura do Estado moderno como uma forma que, ao menos no discurso, se constrói pela separação entre sociedade política (aparelho administrativo e burocrático) e sociedade civil (instituições que formam o indivíduo - família, escola, igreja, meios de comunicação, além da estrutura econômica). Esta separação, embora fictícia, 


\section{movimento \\ faculdade de educação - programa de pós-graduação em educação \\ universidade federal fluminense issn 2359-3296 \\ ano 3 número 5 - 2016}

produz no senso comum um modo de vida que se reduz ao que Gramsci denomina "econômico-corporativo" (Q. 13, p. 1590).

A natureza do Estado moderno se manifesta no modo como se produzem e se desenvolvem as relações de forças econômicas, sociais e políticas; a definição de Estado apresenta-se no bojo de críticas a interpretações liberais: "o Estado é o instrumento para adequar a sociedade civil à estrutura econômica” (Q. 10, p. 1254); ou demonstrando que na "noção geral de Estado entram elementos que também são comuns à noção de sociedade civil (Estado = sociedade política + sociedade civil, isto é, hegemonia revestida de coerção)" (Q. 6, p. 763-764). Ou ainda no Caderno 6: "por Estado deve entender-se, além do aparato de governo, também o aparato 'privado' de hegemonia ou sociedade civil" (Idem, p. 801). Ou ainda: na polêmica "sobre as funções do Estado (como organização políticojurídica em sentido estrito) a expressão 'Estado - veilleur de nuit' ... significaria um Estado cujas funções se limitam à tutela da ordem pública e do respeito às leis". Em tal regime liberal, a "direção do desenvolvimento histórico pertence às forças privadas, à sociedade civil que é, também ela, 'Estado', ou melhor, é o próprio Estado" (Q. 26, p. 2302).

A separação entre sociedade política (denominada Estado no sentido governativo) e sociedade civil é, portanto, um equívoco teórico ou uma mistificação ideológica para estabelecer um processo neutro de gestão pública. Um dos momentos em que Gramsci se posiciona criticamente é no Caderno 13, a propósito da crítica ao economicismo e ao livre cambismo: tais "degenerações", assinala Gramsci:

[...] baseiam-se num erro teórico cuja origem prática não é difícil de identificar, ou seja: baseia-se na distinção entre sociedade política e sociedade civil que, de 


\section{movimento \\ faculdade de educação - programa de pós-graduação em educação \\ universidade federal fluminense issn 2359-3296 \\ ano 3 número 5 - 2016}

distinção metódica, é transformada e apresentada como distinção orgânica. Assim, afirma-se que a atividade econômica é própria da sociedade civil e que 0 estado não deve interferir em sua regulamentação (Q. 13, p. 1589-90).

Mas, continua Gramsci, "na realidade dos fatos, sociedade civil e Estado se identificam", de modo que toda política econômica, quer se assuma claramente ou não, também regulamentada, "de caráter estatal, introduzida e mantida por via legislativa, coercitiva" (Q. 13, p. 1590). A partir destas colocações Dias (2014, p. 20) nos esclarece que a "leitura da sociedade civil como lugar do consenso e em oposição ao Estado não é apenas não- gramsciana, mas profundamente antigramsciana".

Da nossa perspectiva, a leitura liberal de Gramsci, efetuada a partir de uma leitura parcial dos Cadernos, consiste tanto em dissociar sociedade política de sociedade civil, coerção e consenso, entendidos não em articulação, mas em oposição dicotômica, quanto em identificar a sociedade política com o Estado, posição que pressupõe a separação entre economia e política, atribuindo ao "Estado" (sociedade política) a mera função de governo.

Para Gramsci, sociedade política e sociedade civil se articulam e se identificam, ambas formando o Estado. E isso serve para qualquer Estado, mesmo o liberal. A separação entre estas duas instâncias, mesmo que para fins didáticos, altera o significado do texto de Gramsci e tem sido o caminho para apresentá-lo como um liberal, com graves consequências na compreensão da hegemonia e da luta de classes. A explicitação da noção de Estado aparece em outros Cadernos, como o 12: 


\section{movimento}

faculdade de educação - programa de pós-graduação em educação

universidade federal fluminense issn 2359-3296

ano 3 número 5 - 2016

Pode-se, por agora, fixar dois grandes 'planos' superestruturais, aquele que se pode chamar 'sociedade civil', isto é, o conjunto de organismos vulgarmente chamados 'privados' e aquele da 'sociedade política ou Estado', que correspondem à função de 'hegemonia' que o grupo dominante exerce em toda a sociedade e àquela de 'domínio direto' ou de comando que se exprime no Estado e no governo 'jurídico'. Estas funções são precisamente organizativas e conectivas (Q.12, p. 1518-19).

São dois planos que se articulam para efetivar o exercício da hegemonia: no âmbito da sociedade política se exercem as funções de "domínio direto", por meio das políticas públicas e das funções burocráticas, enquanto à sociedade civil, com suas instituições formativas, cabe elaborar o consenso passivo das massas. Este também o funcionamento do Estado no contexto do liberalismo, no qual "ideologia liberal, com sua força e suas fragilidades, pode estar contida no princípio da divisão de poderes"; nos momentos de crise, o complicador "é a burocracia, ou seja, a cristalização do pessoal dirigente que exerce o poder coercitivo e que, a um certo ponto, torna-se casta" (Q. 6, p. 752).

Unidade do Estado na distinção dos poderes: o Parlamento mais ligado à sociedade civil, o Poder Judiciário entre Governo e Parlamento representa a continuidade da lei escrita (também contra o Governo). Naturalmente todos os três poderes são também órgãos de hegemonia política, mas em medida diversa: 1) Parlamento; 2) Magistratura; 3) Governo. E de se notar que ao público faça impressão desastrosa especialmente as transgressões da administração da justiça: o aparelho hegemônico é mais sensível neste setor, que também pode incluir os representantes da polícia e da administração política (Q. 6, p. 752).

Burgio (2014, p. 338-9) salienta que, para o jovem Gramsci, já nos escritos de L'Ordine Nuovo, o "aparelho institucional do Estado parlamentar era considerado um bloco funcional para a manipulação da opinião pública e da vontade coletiva, ou seja, para a salvaguarda do aparato de poder instituído". A democracia 


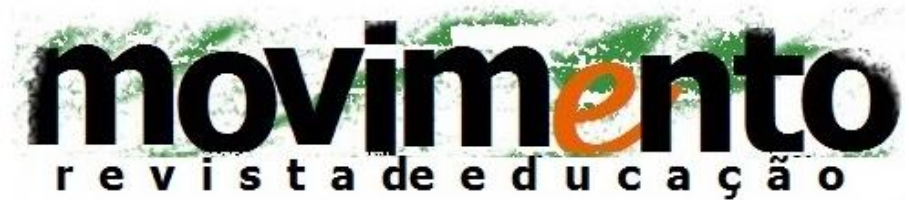 \\ faculdade de educação - programa de pós-graduação em educação \\ universidade federal fluminense issn 2359-3296 \\ ano 3 número 5 - 2016}

burguesa apresentava-se como "uma estrutura tirânica porque meramente formal". A cisão entre a esfera política e a realidade social que, na leitura de Gramsci se constituía na figura liberal do Estado, era uma forma sem conteúdo que "o sistema 'parlamentar' tinha a função de mascarar, legitimar e perpetuar".

Ainda para Burgio (2014, p. 339), o fulcro da crítica gramsciana "é a inconsistência da pretensão de representar a vontade popular à qual as instituições burguesas confiam a própria legitimação". Ou seja, "longe de representar as reais orientações do corpo social, para Gramsci as instituições da democracia parlamentar determinam a sua sistemática negação". E, nos Cadernos do Cárcere, "esta dura invectiva contra a democracia burguesa persiste e até parece aprofundar-se".

O ponto com o qual Gramsci se embate é o sistema parlamentar, os limites da representação, principalmente em relação à vontade popular, a partir da ingerência do poder econômico no processo eletivo e na defesa direta de seus interesses de classe. Para efetivar este mecanismo usa-se da demagogia, definida por Gramsci como "servir-se da massa popular, de suas paixões sabiamente excitadas e alimentadas, para os próprios fins particulares, para suas pequenas ambições"; o parlamentarismo e o sistema eleitoral "oferecem um terreno propício para esta forma particular de demagogia" (GRAMSCI, 1978, p. 772). Estes mecanismos precisam ser desmistificados e, para tanto, é preciso elevar o nível cultural das massas, o que pode acontecer por um movimento de organização política de classe e também por outros mecanismos de educação recíproca que Gramsci salienta ao longo de seus escritos.

A partir deste contexto estrutural podemos refletir sobre os limites e possibilidades das políticas públicas em geral e das fragilidades das lutas por 


\section{movimento \\ faculdade de educação - programa de pós-graduação em educação \\ universidade federal fluminense issn 2359-3296 \\ ano 3 número 5 - 2016}

mudanças sociais no âmbito da democracia burguesa. Para Gramsci, o Estado liberal funciona, para as classes subalternas, mais como uma "aspiração política do que como uma realidade" (CF., p. 05-11), na medida em que se apresenta como garantidor dos direitos individuais e sociais, mas, na realidade, atua em defesa dos interesses do capital. A crença na participação igualitária na política e a crença em um Estado neutro e acima dos antagonismos de classe, sedimentadas no ocultamento da origem econômica e social das desigualdades, são a grande miragem que robustece esta estrutura e que se torna a sua força de conservação (Gramsci, 1982).

A distinção dos poderes como descrita acima por Gramsci, com eleições periódicas para os vários cargos de governo, organizam as relações políticas no âmbito da democracia burguesa. No contexto desta estrutura, o contato direto dos grupos econômicos com as instituições estatais, por meio de eleições nas quais esses grupos investem maciçamente para eleger seus representantes, tornam a sociedade política um mecanismo de preservação dos privilégios e da dominação capitalista. A ilusão de participação igualitária criada nas classes subalternas repercute na forma como estas classes esperam das políticas públicas, sem perceber que o poder econômico determina com antecedência os objetivos e finalidades de tais políticas.

A questão da efetividade das políticas públicas depende da correlação de forças que os grupos sociais conseguem estabelecer na disputa acirrada que se instaura entre os interesses em jogo. Romper com estes limites implica formar uma consciência crítica a respeito das condições sociais próprias da sociedade capitalista. Gramsci empenhou-se ao longo de sua militância política em esclarecer as classes trabalhadoras da necessidade de organizar-se para 0 


\section{$\operatorname{movim}_{\text {revistade educąis }}$}

faculdade de educação - programa de pós-graduação em educação

universidade federal fluminense issn 2359-3296

ano 3 número 5 - 2016

mínimo, que consiste em lutar por direitos sociais no contexto da sociedade capitalista, mas também para o máximo, que se traduz na luta revolucionária.

Nos Cadernos do Cárcere, as críticas ao senso comum para a formação de uma nova concepção de mundo são fundamentais no contexto das relações de hegemonia e da luta por uma nova ordem social e política. A formação política a partir do senso comum precisa partir do fato que este é contraditório porque contém tanto os elementos que formam o imaginário social conservador, quanto os elementos embrionários que, se identificados, podem servir de base para a formação de uma consciência crítica e transformadora. Este tema perpassa os Cadernos enquanto necessidade de elevar as massas até o ponto do pensamento mundial mais desenvolvido (que, em alguns textos, Gramsci entende ser o marxismo):

Quando a concepção do mundo não é crítica e coerente, mas ocasional e desagregada, pertencemos simultaneamente a uma multiplicidade de homensmassa, nossa própria personalidade é composta de maneira bizarra: nela se encontram elementos dos homens das cavernas e princípios da ciência mais moderna e progressista; [...]. Criticar a própria concepção de mundo significa torná-la unitária e coerente e elevá-la até o ponto atingido pelo pensamento mundial mais desenvolvido (Q. 10, p. 1376).

A formação de um pensamento crítico e unitário depende muito do processo de organização política dos grupos subalternos e consiste, basicamente, em articular política e educação, num movimento de educação recíproca que pode esclarecer os interesses e as práticas que identificam uma classe. O que evidenciamos nos escritos de Gramsci é que a luta de classes assume uma dimensão cada vez mais ideológica, sendo necessário criar e fortalecer mecanismos de formação política e cultural dos grupos subalternos. 


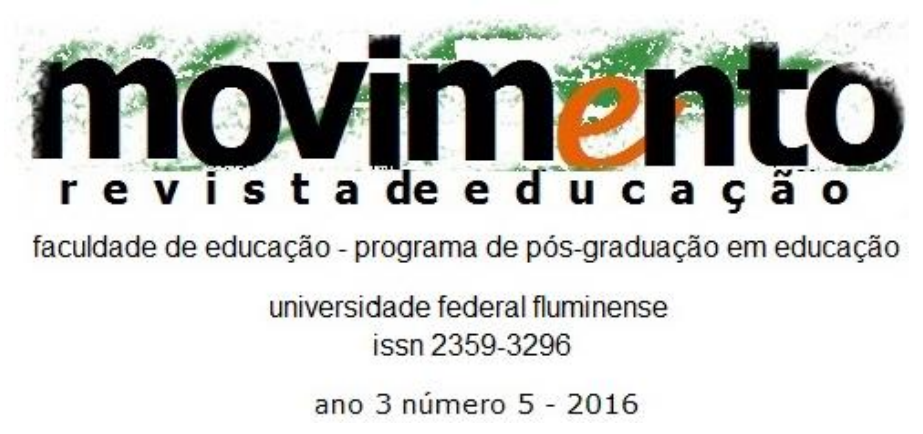

Estes são alguns pressupostos para explicitar as dimensões, os limites e possibilidades das políticas públicas no contexto de uma democracia burguesa.

Notas sobre políticas públicas e disputas sociais:

'Estamos persuadidos que uma verdade só é fecunda quando se fez um esforço para a conquistar, que a verdade não existe em si e para si', mas é uma conquista histórica (GRAMSCl, 1975, p. 63).

Os limites das políticas públicas se colocam tanto pela forma de gestão que se estabelece em uma democracia burguesa quanto pelo entendimento que se tem no senso comum deste conceito. Assim como o conceito de liberdade, também a noção "políticas públicas" é tomada abstratamente, como se tais políticas se referissem ao todo social, visto que "público" pode ser referido tanto ao social em geral quanto ao financiamento provindo do erário público formado dos impostos de toda a sociedade. Muitas abordagens no campo da educação entendem as políticas públicas como ações neutras, capazes de, por si só, possibilitarem transformações efetivas. Esta é uma visão não apenas do senso comum, mas também da intelectualidade, principalmente na área da educação, que alimenta grandes expectativas em relação à possibilidade de mudanças advindas de tais políticas.

No contexto das democracias modernas, na medida em que se expande o capital e o neoliberalismo se propõe como política capaz de resolver as crises mais recentes do capital, os interesses econômicos delineiam cada vez mais profundamente os objetivos políticos da burguesia, que demonstra sua força 


\section{movimento \\ faculdade de educação - programa de pós-graduação em educação \\ universidade federal fluminense issn 2359-3296 \\ ano 3 número 5 - 2016}

conservadora e reacionária na mesma medida em que as classes populares reivindicam seus direitos de participação e de garantia de direitos sociais.

A partir da democracia burguesa e de seus limites, principalmente na realidade brasileira, estas expectativas, em geral, se frustram. Isso porque o Congresso Nacional, a partir de eleições em que o poder econômico determina o quadro eleitoral vencedor, não representa minimamente a sociedade, mas responde a interesses de grupos com base nos quais se elegeram. As bancadas do BBB (Boi, Bala e Bíblia) representam oligarquias agrárias, completadas por representantes dos interesses do capital nacional e estrangeiro. Neste conjunto, a pequena base que expressa os interesses sociais dos subalternos não encontra espaço para a defesa da maioria social oprimida e explorada.

Como acentua Del Roio (2016, p. 5), nesta conjuntura "é a polícia que representa o Estado, não as chamadas 'políticas públicas' que, na verdade, são políticas de construção de uma hegemonia burguesa débil". Com um congresso sem representatividade social, mas sedimentado no poder do capital pouco se pode esperar das políticas públicas. Na Historia do Brasil, marcada por longas fases de regime autoritário e pequenos períodos de frágil democracia, cada vez que nascem movimentos sociais bem organizados, cada vez que se luta, por exemplo, pela reforma agrária, temos golpes de Estado. A força policial e 0 autoritarismo se impõe ante as reivindicações populares.

Esperar resolver problemas sociais gravíssimos com políticas públicas significa, portanto, iludir-se com as possibilidades de mudança. As aspirações políticas no contexto de uma democracia frágil e controlada pelo poder econômico podem se limitar apenas a ações reformistas, paliativas e compensatórias como as que foram efetivadas pelo PT no poder. Não existem possibilidades de ações 


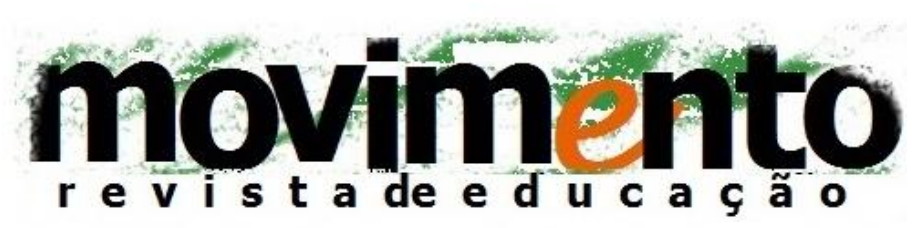

faculdade de educação - programa de pós-graduação em educação

universidade federal fluminense issn 2359-3296

ano 3 número 5 - 2016

transformadoras efetivadas no interior da burocracia estatal ou nos limites de alianças com a classe dominante e parcerias com o capital privado.

Delineiam-se dois quadros precisos de disputas sociais: os movimentos sociais organizados a partir dos interesses das massas que, na medida de suas proporções, podem garantir mudanças; ou as políticas públicas que, na estrutura política da democracia acima descrita e de um poder representativo concentrado nos interesses da classe dominante, podem apenas conseguir respostas paliativas. No primeiro caso, tem-se o caminho da insurreição; no segundo, do reformismo.

Mesmo que as formas de representatividade se alterem, os regimes representativos burgueses continuarão a ter limites significativos de participação para as classes subalternas e é uma ilusão pensar em mudar a sociedade gradativamente a partir do acesso ao poder. O reformismo, em suas várias modalidades, no curso da história política em geral e da socialdemocracia em particular, demonstrou esta afirmação.

Cabe às classes subalternas buscar outros caminhos a partir de sua organização política. Para tanto, a educação em geral e a escola em particular tornam-se instrumentos importantes para a organização política, principalmente quando a escola abre a possibilidade de conhecer os princípios que pautaram as lutas históricas, ou seja, de conhecer e apropriar-se criticamente da cultura historicamente produzida. A leitura crítica da conjuntura, aliada ao conhecimento da história das lutas que geraram grandes transformações, pode servir para a superação do senso comum e a elaboração de uma nova concepção de mundo e superar o ceticismo político. 


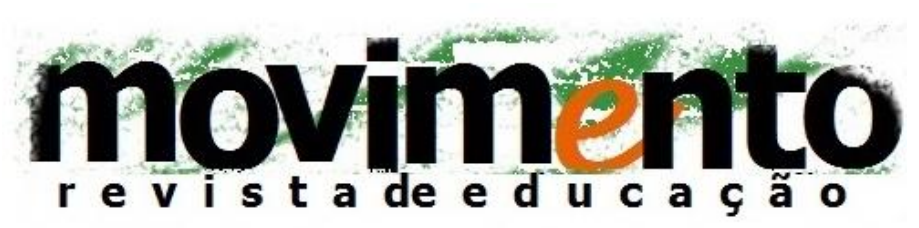

faculdade de educação - programa de pós-graduação em educação

universidade federal fluminense issn 2359-3296

ano 3 número 5 - 2016

Para as classes trabalhadoras educar-se significa identificar as contradições sociais a fim de romper com os estreitos limites da ordem burguesa. Conhecer a estrutura do Estado, os limites ideológicos nas suas novas dimensões, principalmente a partir do contínuo trabalho de desinformação dos meios de comunicação de massa. Educar-se significa formar um pensamento crítico a partir da compreensão da situação real e, a partir desses pressupostos, proporse objetivos claros e demonstrar uma vontade tenaz na sua realização. A liberdade concreta precisa ser construída no dia a dia, num trabalho coletivo de educação recíproca.

\section{Conclusão}

As medidas recessivas tomadas a partir da ofensiva que restaura a política neoliberal incidem principalmente sobre as áreas da educação e da saúde, penalizando as classes subalternas. A educação é um dos direitos fundamentais que só são garantidos se em conjunto com outros direitos como trabalho, saúde, moradia, cultura, etc., ou seja, a educação se efetiva se houverem condições sociais de uma vida digna para os trabalhadores.

Este é o primeiro ponto a ser defendido na conjuntura atual e, a partir dele, a necessidade de lutar não apenas por garantia de direitos, mas por reformas institucionais iniciando por uma reforma política, seguida por uma reforma tributaria e finalmente por uma reforma agrária, todas necessárias para uma retomada do crescimento econômico no Brasil. Como acentua Boito (2016), o "recuo passivo do governo Dilma" dificultou a "definição de estratégias dos movimentos populares na crise atual". Pensamos que não apenas a política 


\section{movimento \\ faculdade de educação - programa de pós-graduação em educação \\ universidade federal fluminense issn 2359-3296 \\ ano 3 número 5 - 2016}

governamental deve ser questionada, mas a passividade das esquerdas em geral, muito críticas entre si a partir das várias tendências que representam, mas distantes das massas.

A esta situação se agregam as características já descritas do nosso Congresso Nacional, em sua maioria defensor do poder econômico nacional e estrangeiro, sem maiores preocupações com os graves problemas sociais que enfrentamos. Este quadro nos mostra que as relações de força estão desequilibradas, debilitando as expectativas em relação à efetividade das políticas públicas. Apesar disso, o campo de disputas sociais está aberto e as forças promissoras da juventude convidam para a mobilização e a resistência.

Para tanto, faz-se necessário conhecer a organização e o funcionamento do Estado e como a veiculação de conceitos abstratos dificulta a formação de um pensamento crítico. Por isso, retomamos alguns fragmentos do pensamento de Gramsci para esclarecer as relações políticas a partir da noção liberal de Estado contraposta ao conceito gramsciano, a partir dos quais se colocam também os limites do reformismo, cuja base é uma visão econômico-corporativa das relações sociais e políticas.

As breves observações a respeito da relação entre políticas públicas, Estado e educação visam a estabelecer um elo entre teoria e prática, iniciada com uma breve análise da crise do capitalismo contemporâneo, a fim de mostrar como a situação presente se desdobra no contexto das relações econômicas, políticas e ideológicas, delimitando as expectativas em relação a tais políticas. As políticas neoliberais, em linhas gerais, fracassaram e as promessas das medidas recessivas que se começa a colocar em prática só podem consolidar o acirramento das contradições sociais. 


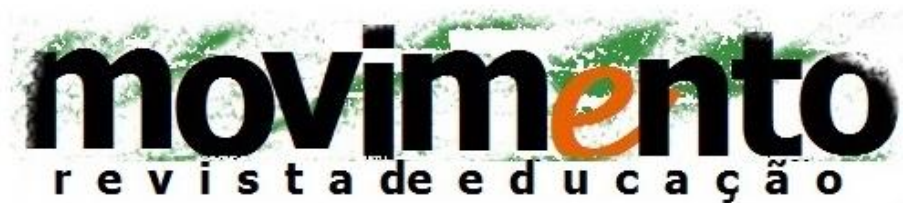 \\ faculdade de educação - programa de pós-graduação em educação \\ universidade federal fluminense issn 2359-3296 \\ ano 3 número 5 - 2016}

Acentuamos ainda a atualidade do pensamento de Gramsci, que nos possibilitou esta leitura, principalmente na explicitação da noção de Estado e das dimensões ideológicas que o exercício da hegemonia assume no contexto da democracia burguesa. Na nossa leitura, a atualidade de Gramsci está, precisamente, em explicitar uma estrutura que continua vigente e, em Estados que historicamente apresentam uma tradição autoritária, como o Estado brasileiro, assume um distanciamento das massas que nem se procura ocultar. A dimensão pública se mistura com a privada de uma forma promíscua e as chamadas "políticas públicas" assumem uma dimensão abstrata que possibilita ampliar os mecanismos de manipulação a favor do poder instituído.

Por que é tão difícil para as classes subalternas perceberem este ardil? A resposta se encontra na dimensão da ideologia na formação do senso comum e de um consenso passivo, ou ainda na crença divulgada pela própria socialdemocracia de que é possível mudar a sociedade pacificamente, com pequenas reformas, ou na possibilidade de mudanças a partir de concessões "pelo alto", num movimento de "revolução passiva".

Tratamos da educação da perspectiva da formação social que se recebe no curso da vida e que se traduz em concepções de mundo e de senso comum. As expectativas que os educadores em geral apresentam em relação às políticas públicas e à gestão resultam, muitas vezes, de uma abordagem abstrata dos conceitos, bem como de um entendimento permeado pela neutralidade gerada por esta perspectiva abstrata. Entretanto, a luta por políticas que contemplem a educação pública gratuita e de qualidade continua sendo muito importante em defesa das classes subalternas. Até porque a educação pública nunca foi 


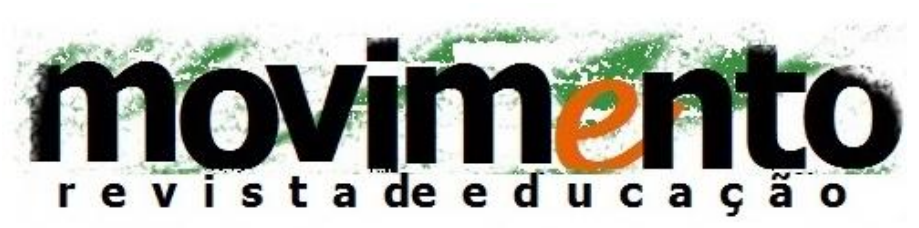

faculdade de educação - programa de pós-graduação em educação

universidade federal fluminense issn 2359-3296

ano 3 número 5 - 2016

gratuita, mas paga com impostos que, no curso de nossa história, tem penalizado as classes trabalhadoras.

A eficácia política da ideologia se apresenta no modo como se abordam os assuntos no processo de aprendizagem. Como dizia Benjamin, as palavras são cavernas, ou seja, não são neutras, mas são mistérios a desvelar, devendo ser apresentadas com seu significado histórico e não como sendo naturais. Quando um conceito se naturaliza assume uma alta eficácia conservadora. Gramsci acentua que a linguagem é política, instrumento de domínio ideológico. E o nosso pensador Paulo Freire mostrou aos pedagogos como se efetiva na prática de alfabetização esta dimensão histórica.

Todas estas observações mostram que a educação se articula com a política e, para as classes subalternas, a tarefa pedagógica assume importância se consistir em desmistificar a linguagem, a política e todas as demais relações a partir da demonstração cotidiana da dimensão histórica da vida, da sociedade e do conhecimento. Embora seja uma luta como a de David contra Golias, os gigantes sempre têm um "calcanhar de Aquiles", basta sabermos descobrir como atingí-lo.

\section{Referências}

BOITO, Armando. A natureza da crise política brasileira. Artigo publicado no Le Monde Diplomatique - Brasil. Número 104, março de 2016.

BURGIO, Alberto. Gramsci: il sistema in movimiento. Roma: Derive-Approdi, 2014. 


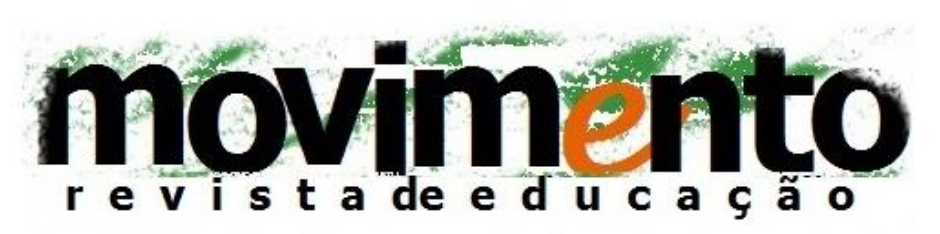

faculdade de educação - programa de pós-graduação em educação

universidade federal fluminense issn 2359-3296

ano 3 número 5 - 2016

DEL ROIO, Marcos. Prefácio. In: SCHLESENER, A. H.; MASSON, G.; SUBTIL, M. J. Marxismo(s) e Educação. Ponta Grossa: Ed. UEPG, 2016.

DURANTE, L. Gramsci e os perigos do cosmopolitismo. Educação em foco Revista de Educação. UFJF, v. 5, n. 2, Set./Fev/ 2000/2001.

DIAS, Edmundo Fernandes. Notas sobre hegemonia. In: SCHLESENER, A. H.(Org.) Filosofia, Política e Educação - leituras de Antonio Gramsci. Curitiba: UTP. 2014.

GRAMSCI, Antonio. Scritti giovanili (19|4-|9|8). Torino : Einaudi Editore, 1975. . L'Ordine Nuovo (1919-1920). Torino: Einaudi, 1975b. . Quaderni del Carcere. Torino: Einaudi, 1978. . La Città Futura (1917-1918). Torino: Einaudi, 1982.

LOSURDO, Domenico. A luta de classes: uma história política e filosófica. São Paulo: Boitempo, 2015.

MASTELLONE, Salvo. (Org.), Gramsci: i “Quaderni del Carcere”- una riflessione politica incompiuta. Torino: UTET Libreria, 2002.

MORDENTI, Raul. Gramsci e la rivoluzione necessaria. Roma: Riuniti, 2007.

RAPONE, Leonardo. Cinque anni che paiono secoli - Antonio Gramsci dal socialismo al comunismo (1914-1919). Roma: Carocci, 2011.

SCHLESENER, Anita Helena. Revolução e Cultura em Gramsci. Curitiba: UFPR, 2002.

SCHLESENER, A. H. A linguagem e seu significado político e pedagógico a partir dos escritos de Gramsci. In: GOMES, V. C., SOUSA, J. R. e rabelo, J. J. (Orgs.). Gramsci, educação e luta de classes. Fortaleza: Imprensa Universitária, 2015. 